\title{
O PROCESSO DE ESCOLARIZAÇÃO NO MUNICÍPIO DE MANDAGUARI-PR
}

\author{
Silvana Rodrigues Malheiro Huss ${ }^{1}$ \\ Maria Cristina Gomes Machado \\ Universidade Estadual de Maringá-UEM
}

\section{RESUMO}

O presente artigo tem como propósito apresentar os resultados finais do trabalho dissertativo desenvolvido no mestrado em Educação, ofertado pela Universidade Estadual de Maringá no período de 2010 a 2012. Pretendeu-se, neste estudo, responder a seguinte indagação: Como ocorreu o processo de escolarização no município de Mandaguari-PR durante o período de 1949 até o ano de 1988?. Para tanto, discutiu-se a colonização norte paranaense e a história do município de Mandaguari, focalizando o debate acerca da formação dos grupos escolares brasileiros e paranaenses, visto que a sua constituição contribuiu para o processo de institucionalização dos primeiros estabelecimentos escolares mandaguarienses. A realização do trabalho dissertativo contribuiu para a história da educação e não apenas para a educação em Mandaguari-PR, por reunir apontamentos para outros pesquisadores que desejam aprofundar estudos sobre como ocorreu o processo educacional, histórico e econômico no norte novo paranaense.

Palavras-chave: Educação. História da Educação. Educação escolar. Escola pública. Município de Mandaguari - PR.

\section{THE PROCESS OF SCHOOLING IN THE CITY OF MANDAGUARI-PR}

\begin{abstract}
The present article has as its purpose to present the final results of the work developed in dissertational Masters in Education, offered by State University of Maringá in the period 2010 to 2012. The intention was to answer the following question: How was the process of schooling in the municipality of Mandaguari-PR over the period from 1949 to the year of 1988? To do so, we discussed the settlement in the North of Paraná and the history of the city of Mandaguari. We also focused on the debate about the education of school groups in Parana Brazil, since its formation contributed to the institutionalization of the first educational institutions in Mandaguari. The completion of the dissertational paper contributed to the history of education as a whole and not just for the education in Mandaguari-PR. It brought together contributions towards other researchers who desire to deepen studies on how the educational, historical and economic development process occurred in the so called new Northern Paraná.

Keywords: Education. History of Education. School education. Public school. City of Mandaguari - PR.
\end{abstract}




\title{
Introdução
}

O presente estudo tem como objetivo apresentar os resultados finais do trabalho dissertativo intitulado: $O$ processo de escolarização no município de Mandaguari-Pr (1949-1988). O estudo possibilitou a compreensão não apenas das primeiras iniciativas de escolarização no referido município, como também do contexto paranaense e brasileiro, mediante levantamento das fontes documentais.

O pesquisador tem diante de si um longo processo, marcado por inúmeros desafios, ele não constrói a história, mas é ele quem aponta os caminhos para o desenvolvimento da pesquisa. O pesquisador não compreenderá o passado em sua totalidade, apenas reconstituirá fragmentos da história, tendo como instrumentos para seus estudos vestígios que a representam e que podem ser denominados: conjunto de fontes. Pode-se considerar que o conjunto de fontes são primordiais e possibilitam o desenrolar de uma pesquisa, se não há fontes e problematização, não existe pesquisa. Sobre a origem das fontes Saviani (2004), destaca:

\begin{abstract}
As fontes históricas estão na origem, constituem o ponto de partida, a base, o ponto de apoio da construção historiográfica que é a reconstrução, no plano do conhecimento, do objeto histórico estudado. Assim as fontes históricas não são a fonte da história, ou seja, não é delas que brota e flui a história. Elas, enquanto registros, enquanto testemunhos dos atos históricos, são a fonte do nosso conhecimento histórico, isto é, é delas que brota, é nelas que se apóia o conhecimento que produzimos a respeito da história. [...] São documentos vestígios, indícios que foram acumulando-se ou foram sendo guardados, aos quais recorremos quando buscamos compreender determinado fenômeno. [...] os mencionados objetos só adquirem o estatuto de fonte diante do historiador que, ao formular o seu problema de pesquisa, delimitará aqueles elementos a partir dos quais serão buscadas as respostas às questões levantadas. Em consequência, aqueles objetos em que real ou potencialmente estariam escritas as respostas buscadas erigir-se-ão em fontes a partir das quais o conhecimento histórico referido poderá ser produzido. (SAVIANI, 2004, p. 5-7).
\end{abstract}

Desse modo, é possível entender que as fontes, especificamente as de uma instituição escolar, são todos os registros encontrados em arquivos escolares ou fora dos mesmos, que podem ser utilizados - documentos oficiais, cadernos de planejamento dos professores, fotos, livros antigos do colégio - e que permitem a compreensão da escola na época em foi instituída e o que ela representa na contemporaneidade.

Segundo Miguel (2008), os documentos oficiais, sejam eles leis ou relatórios de governadores, contribuem para o entendimento das instituições escolares existentes. Embora os documentos não falem por si, eles podem ser questionados e traduzem, em seu interior, o contexto de um determinado momento histórico, etapa que se considera relevante para este estudo.

O trabalho dissertativo utilizou como procedimentos metodológicos a pesquisa bibliográfica, documental e qualitativa. No âmbito documental e bibliográfico, foi realizado o levantamento do conjunto de fontes que permitiram compreender o processo de escolarização mandaguariense, considerando o período de 1949 a 1988. Para a organização do conjunto de fontes, foram pesquisados os arquivos institucionais, a documentação escolar do município, os acervos da biblioteca, da secretaria da educação, os arquivos pessoais dos sujeitos entrevistados, entre outros. Desse levantamento, destacam-se os 
trabalhos regionais que tratam da história do município citados anteriormente de Silva (1982) e de Elizabeth Ana Fontes e Nair de Matos Bianchini (1987), bem como o trabalho mimeografado organizado pelo professor Pedro Mioto (1977), disponível na documentação escolar do município.

Outros documentos merecem destaque: a cópia do Projeto de Cooperação e Assistência Técnica ao Ensino Municipal de Mandaguari - Promunicípio (Diagnóstico), elaborado em 6 de outubro de 1977, disponível na Biblioteca Municipal Dr. Alcir Castelo Branco; o Decreto $\mathrm{n}^{\circ}$. 9.137, de 3 de dezembro de 1949, que criou o Ginásio de Mandaguari(COLÉGIO ESTADUAL VERA CRUZ, 1959a,n.p); o Decreto no ${ }^{\circ}$ 19.628, que alterou a denominação do Ginásio de Mandaguari para "Vera Cruz", de 9 de novembro de 1955(COLÉGIO ESTADUAL VERA CRUZ,1959b,n.p); o Decreto nº. 4019, de 13 de outubro de 1977 que autorizou o funcionamento do Complexo Escolar Professora Hilda de Oliveira - Ensino de $1^{\circ}$ e $2^{\circ}$ Graus e reuniu no mesmo estabelecimento: o Colégio Estadual Vera Cruz, o Colégio Estadual Barão do Cerro Azul, a Escola Normal Colegial Estadual Princesa Izabel, Escola de Aplicação Gabriela Mistral e a Escola de Artes Industriais (COLÉGIO ESTADUAL VERA CRUZ, 1977,n.p); o Decreto n. 2.057, de 11 de outubro de 1977, que alterou a redação dos artigos $1^{\circ}$ e $2^{\circ}$ do decreto 4.019(COLÉGIO ESTADUAL VERA CRUZ, 1980, n.p); Resolução nº 253 de 28 de janeiro de 1982 que estabelece o reconhecimento do curso de $2^{\circ} \mathrm{Grau}$ - Regular com as seguintes habilitações: Contabilidade, Magistério e Básica em saúde (COLÉGIO ESTADUAL VERA CRUZ, 1982, n.p); Resolução ${ }^{\circ}$. 4.094 de 22 de agosto de 1985 estabelece o reconhecimento do curso de $2^{\circ}$ Grau Regular- Propedêutico no Colégio Estadual Vera Cruz- Ensino de $1^{\circ}$ e $2^{\circ}$ Graus (COLÉGIO ESTADUAL VERA CRUZ, 1985a, n.p); Resolução n 2.607 de 25 de junho de 1987, reconhece o Curso de Formação de Professores para o Magistério PréEscolar (COLÉGIO ESTADUAL VERA CRUZ, 1987, n.p); atas de exames; documentos oficiais; decretos de criação das escolas; livros de registros pertencentes às instituições; registros particulares de ex-professores; conteúdos bimestrais utilizados pelas instituições e fontes iconográficas.

No que se refere à abordagem qualitativa, foram realizadas, no período de maio a junho de 2010, entrevistas, por intermédio de questionários semiestruturados, previamente agendadas. A população da pesquisa permitiu retratar a memória oral de oito professores mandaguarienses que contribuíram e contribuem para o campo da história da educação. Durante as entrevistas, os sujeitos puderam expor outras questões a respeito da escolarização, da história do município, das características das escolas, dos conteúdos trabalhados. Alguns sujeitos entrevistados cederam cadernos, provas, fotos que permaneceram registrados ao longo dos anos em seus arquivos pessoais, possibilitando o enriquecimento do referido estudo.

O referido estudo será dividido em duas seções. Na primeira seção, intitulada $A$ colonização do Paraná e a fundação do município de Mandaguari, aborda-se a história da colonização paranaense, bem como os antecedentes que possibilitaram o desbravamento do norte novo, evidenciando o processo histórico do município. Na segunda seção intitulada, $O$ processo de escolarização do município de Mandaguari apresenta-se o processo de escolarização no município de Mandaguari-PR, considerando aspectos que influenciaram a sua constituição. Focaliza-se o debate acerca da escola pública primária, bem como a origem dos grupos escolares brasileiros e paranaenses, visto que a sua constituição contribuiu para o processo de institucionalização dos primeiros estabelecimentos escolares mandaguarienses. 


\section{A Colonização do Paraná e a fundação do município de Mandaguari}

Sobre a ocupação do território paranaense por diferentes populações indígenas, Noelli e Mota (1999, p. 5) destacam que o Estado, “[...] vem sendo continuamente habitado por diferentes populações humanas há cerca de 7000 anos, de acordo com os vestígios materiais mais antigos encontrados pelos arqueólogos". Sobre a formação da população paranaense destaca-se a contribuição de Lazier (2003), que considera o Estado como "a terra de todas as gentes":

Partindo da premissa que o atual território do Estado do Paraná não possui população autóctone, pode-se afirmar que todos que participaram do processo de ocupação da região são imigrantes, a começar pelos préceramistas e pré-colombianos, ou seja, as famílias linguísticas Jê e TupiGuarani. Depois, vieram os colonizadores espanhóis e portugueses. Em seguida, os navios-negreiros trouxeram os africanos escravizados. No fim do século XIX e início do século XX, vieram os europeus e os Asiáticos. A partir de 1930, o norte, o oeste e o sudoeste do Paraná foram ocupados por migrantes de São Paulo, Minas Gerais, Rio Grande do Sul, Santa Catarina e nordestinos. Em verdade, o Paraná é a terra de todas as gentes. Tornou-se uma região multicultural e multirracial, uma mistura de sangue e cultura, talvez única no mundo pela sua diversidade. Essa é uma de suas particularidades, talvez sua identidade. (LAZIER, 2003, p. 89).

A ocupação dos povos imigrantes nas regiões paranaenses foi favorecida pelas condições climáticas. Esses povos deram suas contribuições nas técnicas da agricultura, hábitos alimentares de diversas regiões, construções civis e públicas, abertura de estradas, denominações de cidades, entre outras, construindo desse modo a "identidade" do território paranaense.

No século XVIII, a região de Curitiba apresentava uma população em torno de 1400 pessoas. Contava com um clima favorável e terras férteis para a agricultura e a pecuária, entretanto, em relação ao meio geográfico, dispunha de fatores negativos, como explicita Wachowicz (1988, p. 66): “[...] a Serra do Mar, de difícil transposição, encoberta pela mata atlântica, muito intricada, dificultava aos curitibanos a venda de sua produção agrícola ou pastoril", contudo, apesar das dificuldades apresentadas no início, anos depois, Curitiba se desenvolveu e foi instituída a capital do território paranaense.

Em relação às estatísticas da população paranaense entre os séculos XVIII e XIX, Prosser (2004, p. 36) aponta que a presença dos negros foi "[...] progressivamente diminuindo, à medida que aumentava a entrada do imigrante europeu". Aos poucos, os imigrantes europeus assumiram o processo de colonização e tornaram-se proprietários de várias regiões, propiciando o desenvolvimento de uma nova classe média paranaense. $\mathrm{O}$ imigrante europeu "[...] tornou-se personagem típico da população paranaense, criou a agricultura de abastecimento, a pequena propriedade e participou da economia da madeira, do gado e do mate, além de ter concorrido para a modificação do aspecto urbano" (PROSSER, 2004, p. 40). Acrescenta o mesmo autor:

De maneira geral, essa expressiva massa imigratória, sua riqueza e variedade étnico-cultural, aliada ao elemento ibérico, negro e indígena estabelecidos na região inicialmente pelo ouro, depois pela criação do gado, pela erva-mate e pela madeira, conferiu ao Paraná uma tipologia humana específica. Plasmou-se uma sociedade que enfatizava a educação, a cultura e as atividades intelectuais e técnicas, peculiares aos 
países de origem dos estrangeiros aqui radicados e presentes nas preocupações de alguns dos dirigentes da Província e do Estado do Paraná, entre eles, os senhores do mate. (PROSSER, 2004, p. 40-41).

Os imigrantes contribuíram para o desenvolvimento do comércio, indústrias e diversas atividades artesanais, crescimento das cidades, alteração da arquitetura religiosa. Desse modo, “[...] italianos, alemães, poloneses, franceses e pessoas de outras etnias vieram dar uma nova feição para as cidades" (TRINDADE; ANDREAZZA, 2001, p. 55.), uma vez que, até meados do século XIX, grande parcela dos povos imigrantes vivia na zona rural, desse modo "[...] começa a florescer uma economia tipicamente urbana, e principalmente, a aumentar a população residente" (TRINDADE; ANDREAZZA, 2001, p. $55)$.

No final do século XIX, a expansão da pecuária, da mineração, o crescimento da produção e comércio da erva-mate favoreceu o desenvolvimento do território paranaense possibilitando "[...] sonhar com a autonomia política da Comarca de Curitiba" (LAZIER, 2003, p. 83).

Ante tal progresso, o projeto emancipacionista em favor do território paranaense foi obtido em 02 de agosto de 1853 o Estado paranaense torna-se Província do Império, por intermédio da Lei $\mathrm{n}^{\circ}$. 704, sancionada pelo Imperador D. Pedro II, que tornou "[...] o Paraná a mais jovem província do Império" (WACHOWICZ, 2001, p. 120). Seu primeiro presidente foi Zacarias de Góes e Vasconcelos, ainda no período provincial, seu governo teve uma duração de 36 anos, de 1853 a 1889 (ano da Proclamação da República).

Os anos de 1875 a 1920 representaram um período de grandes transformações para a capital paranaense, favorecido pelos ciclos da mineração, pecuária e erva-mate, propiciando o enriquecimento de várias famílias e o processo de urbanização de Curitiba, podendo ser "[...] observadas, também no desenho urbano da cidade, nas grandes mansões construídas pelos ervateiros [...]" (PROSSER, 2004, p. 34).

$\mathrm{Na}$ década de 1920, o cenário brasileiro pode ser caracterizado por acontecimentos de ordem social, cultural e política como a crise do café, a Semana da "Arte Moderna", a rebelião dos jovens oficiais do Forte de Copacabana, a campanha civilista proposta por Rui Barbosa, o movimento tenentista e os movimentos promovidos pela classe de trabalhadores, que consolidaram a "[...] a visão nacionalista, vindo a interferir no processo da modernização do país” (CAMARGO, 2006, p. 107).

A modernização da capital paranaense contribuiu para a ocupação das terras do norte, “[...] surgindo então às cidades de Cambará, Bandeirantes, Cornélio Procópio e Andirá" (TRINDADE; ANDREAZZA, 2001, p. 67.), região que, posteriormente, foi denominada norte velho.

O Estado do Paraná se diferenciava do restante do país visto que o setor econômico se amparava na produção de erva-mate, madeira e no desenvolvimento da cafeicultura, favorecendo o nascimento de cidades em todo o se território. Desenvolveram-se cidades como Londrina, Rolândia, Arapongas, Apucarana, Mandaguari, Maringá, Cianorte e Umuarama na região denominada Norte Novo. Lazier (2003) destaca: "O que influenciou na rápida ocupação do norte foi a cultura do café que em 1947 representava 11,4 \% da produção nacional e em 1962 passou para 62,8\%" (p. 142-143).

A colonização dos territórios norte novo e novíssimo paranaense teve início com a vinda da missão de Montagu, de origem inglesa, convidada pelo presidente Arthur Bernardes, com o intuito de estudar a situação econômica, financeira e comercial do país. Para tanto, o governo brasileiro solicitou aos ingleses "[...] um estudo para reformular o sistema de arrecadação dos impostos federais" (WACHOWICZ, 2001, p. 267). A missão inglesa chegou a territórios brasileiros em meados de 1924, com o intuito de investir no 
plantio de algodão. Inicialmente, a empresa Brazil Plantations Syindicate Ltda. se estabeleceu em Londres, entretanto, como não obteve resultados satisfatórios, resolveu fundar o Paraná Plantations, sediado em Londres, e a "Companhia de Terras do Norte do Paraná" sediada em São Paulo. Esta situação foi mantida até 1944, quando os acionistas brasileiros adquiriram a totalidade das ações da Companhia de Terras, que passou a denominar-se Companhia Melhoramentos do Norte do Paraná.

A Missão Montagu trouxe, ao Brasil, Lord Lovat (um dos grandes nomes da colonização do norte novo e novíssimo paranaense), que trabalhava como assessor de assuntos de agricultura e florestamento da Sudan Cotton Plantations, sendo de grande relevância o processo de colonização do território paranaense. De um lado, estava Lord Lovat, que buscava no território brasileiro informações sobre a agricultura e terras para o plantio de algodão, de outro lado, estavam os fazendeiros que ocupavam o norte velho e procuravam investidores para continuar as obras da ferrovia São Paulo-Paraná, iniciadas por fazendeiros que paralisaram as obras devido a dificuldades financeiras.

Os interesses em questão deram início à colonização do norte novo e novíssimo paranaense, resultando na Companhia de Terras do Norte do Paraná, tendo como primeiro presidente o advogado Antonio Barros Moraes. De acordo com Wachowicz (2001), em 1931, a Companhia de Terras Norte do Paraná já havia vendido 3.000 alqueires do referido território. Os compradores eram atraídos por preços vantajosos e pelas terras férteis da região.

Lazier (2003) destaca que a visita de Lord Lovat ao Brasil resultou na criação da Brazil Plantations Syndicate Ltda. em Londres, cujo objetivo era colonizar as terras do norte paranaense. Assim, os ingleses:

[...] compraram terras entre os Rios Paranapanema, Tibagi e Ivaí. Em 1925, adquiriram diretamente do governo do Estado 450.000 alqueires por apenas 8.712 contos de réis. Pagaram por alqueire o equivalente a 5 kg de feijão ou o salário de um carpinteiro. Foi um negócio ilícito. Em 1927, já possuíam 515.000 alqueires, coberto de matas (LAIZIER, 2003, p. 142).

O objetivo da Companhia era promover a colonização e o desenvolvimento da área que possuía, entretanto as dificuldades causadas pela Segunda Guerra Mundial levaram os ingleses a colocarem à venda a Companhia de Terras do Norte do Paraná, que foi adquirida por grupos paulistas, dando origem, no ano de 1944, à Companhia Melhoramentos Norte do Paraná, que foi a responsável pela fundação da cidade de Mandaguari-PR. Wachowicz (2001, p. 271) explica que as cidades de Londrina, Cambé, Rolândia, Arapongas, Mandaguari, Apucarana, Jandaia do Sul, Maringá, Cianorte, Umuarama, Guaira entre outras, foram fundadas por essas duas companhias no norte do Paraná. A Companhia Melhoramentos Norte do Paraná possuía sede no patrimônio de Três Bocas (atualmente cidade de Londrina), onde se localizava o núcleo da colonização.

No antigo patrimônio de Três Bocas, a 22 quilômetros de Jataizinho, foi levantado um acampamento em 1929. Ali foram instalados os escritórios da Companhia de Terras Norte do Paraná e iniciada uma infra-estrutura urbana. [...] Foi tão grande a movimentação de compras de terras, que em apenas um determinado ano, a companhia chegou a vender 60.000 alqueires. Ao lado de compradores nacionais era grande também o número de estrangeiros: italianos, portugueses, espanhóis, alemães, japoneses, poloneses, ucranianos, etc. (WACHOWICZ, 2001, p. 271.). 
A obra colonizadora contou com a ajuda de famílias vindas de São Paulo e Minas Gerais, que chegaram, em 1930, ao Patrimônio de Três Bocas. Os colonizadores participaram de expedições estimuladas pela Companhia, que tinha como principal objetivo a colonização do vasto território paranaense, caracterizado, na publicação da Companhia Melhoramentos do Norte do Paraná (1975, p. 63), como uma “[...] estrada rude, penetração serpeante pela floresta que espanta e extasia, [...]", ressaltando que os desbravadores encontraram um território fértil, que propiciava o desenvolvimento nas terras roxas do norte paranaense.

Em 1930, os colonizadores/desbravadores chegaram ao patrimônio de Três Bocas, caracterizado como um "[...] acampamento de pioneiros, aberto na clareira circundada pela imponente mata de terra roxa, onde sobressaíam grandes perobas e paus-d'alho", um cenário que revelava os primeiros passos para o desenvolvimento da região em meio a algumas casas de madeira e poucas ruas.

\begin{abstract}
A década de 1930 foi amplamente importante para a Companhia em termos de concretização de objetivos. A partir de Londrina, que nasce do patrimônio de Três Bocas, sendo transformado em município em 3 de dezembro de 1934, através do Decreto Estadual nº. 2519, foram criadas novas cidades, que nasciam como povoados de Londrina e logo se emancipavam. Numa sequência, podemos ver Cambé, Rolândia, Arapongas, Apucarana e Mandaguari. Todas fundadas na década de 1930, mesmo que a emancipação de algumas, como Mandaguari, só ocorresse na década de 1940. (SILVA, 1982, p. 2).
\end{abstract}

A Companhia de Terras do Norte do Paraná adotou estratégias favoráveis à colonização paranaense no que tange, em especial, à definição das áreas desbravadas, “[...] as cidades a se tornarem núcleos econômicos de maior importância seriam demarcadas de cem em cem quilômetros, aproximadamente" (COMPANHIA..., 1975, p. 76). Distantes dos núcleos econômicos, de 10 a 15 quilômetros, seriam fundados "[...] os patrimônios, centros comerciais e abastecedores intermediários", contribuindo para o desenvolvimento de muitos outros núcleos econômicos. Desse modo, é fundamental considerar que as cidades fundadas obedeciam "[...] a um plano urbanístico, previamente estabelecido" (COMPANHIA..., 1975, p. 125), no qual as ruas e praças abertas estavam em favor do relevo de cada território colonizado.

A Companhia Melhoramentos Norte do Paraná considerou como núcleo básico da colonização as cidades que se distanciavam 100 quilômetros umas das outras, conforme proposto pelos ingleses, destacando cidades como Londrina, Maringá, Cianorte e Umuarama, que foram planejadas para se transformarem em grandes metrópoles. Entre esses núcleos, ao serem fundados os patrimônios menores, alguns deles, entretanto, transformaram-se em grandes cidades. Como exemplo, podem ser destacadas as cidades de Apucarana, Cambé, Rolândia, Arapongas, Astorga, Nova Esperança e Mandaguari. Foram cidades que "[...] cresceram praticamente por si, pois a Companhia se limitou a planejá-las e a construir um escritório, uma estação de jardineiras e uma escola" (COMPANHIA..., 1975, p. 125).

A Companhia Melhoramentos Norte do Paraná chegou a Vitória (atual município de Mandaguari) em meados de 1937, contribuindo, de modo efetivo, para a ocupação do norte paranaense, "[...] colonizou uma área "correspondente a 546.078 alqueires de terras ou 1.321.499 hectares, ou ainda cerca de 13.166 quilômetros quadrados". (COMPANHIA..., 1975, p. 133). 
Luz (1997) destaca que a colonização do norte paranaense se embasou em pequenas propriedades de cafezais, propiciando "[...] a existência de uma população rural bastante numerosa" (p. 23), todavia as atividades como comércio, prestação de serviços "[...] se concentraram nas cidades, estabelecidas ao longo da estrada de ferro e da rodovia [...]" (p. 23).

A ocupação das terras do norte e novíssimo paranaense iniciada por Lord Lovat em meados da década de 1920 influenciou diretamente no desenvolvimento do município de Mandaguari, que foi colonizado em meados de 1930, pela Companhia Melhoramentos Norte do Paraná. Em 1939, a Companhia Colonizadora, sediada em Londrina, resolveu dar ao povoado de Vitória o nome de Lovat, em homenagem a Lord Lovat, que foi um dos responsáveis pela colonização do território paranaense em meados de 1924. Entretanto o cenário mundial, marcado pela Segunda Guerra Mundial, iniciada em 1939, de certo modo, influenciou especificamente na alteração dos nomes recebidos pelos povoados paranaenses ocupados pela Companhia, visto que, em 1942, o governo brasileiro solicitou aos estados que tivessem cidades com nomes de origem germânica que os substituíssem por nomes de origem brasileira. O governo do Paraná iniciou as trocas, como no caso de Nova Dantzing, que passou a se chamar Cambé, este sim de origem germânica. No entanto, o funcionário responsável por tal mudança acreditou que Lovat (de origem inglesa) caberia na mesma regra, levando-o a escolher outro nome.

Fontes e Biachini (1987), pesquisadores que tiveram acesso aos primeiros mapas do povoado de Vitória, afirmam que consta um ribeirão com a denominação de Mandaguari; alguns colonos afirmaram que o nome é de origem indígena, designando uma espécie de abelha encontrada na região; outros mapas apresentam a denominação Barbacena. Fontes e Biachini (1987) defendem que a definição mais acertada da origem da denominação do município se deve a um ribeirão chamado Mandaguari.

\section{O processo de escolarização no município de Mandaguari}

O termo "processo" vem do latim e significa uma sequência contínua de fatos que apresentam certa unidade, ou que se reproduzem com certa regularidade. É, normalmente, usado para definir algumas teorias e áreas do conhecimento, tais como: processos judiciais; processos trabalhistas; processos criminais; processos seletivos; processos sociais; processo de avaliação; processos legislativos; processo administrativo; processo cognitivo; processo histórico, entre outros.

Entende-se por processo de escolarização mandaguariense as reivindicações do povo, as decisões legais e outras questões que possibilitaram a efetivação da educação. Os depoimentos orais, o conjunto de fontes, enfim as informações obtidas permitiram avançar pela história de Mandaguari e por intermédio desse conjunto de dados possibilitou investigar as primeiras iniciativas de escolarização do referido município.

O processo de escolarização mandaguariense pode ser subdividido em duas etapas, a Educação Rural e a Educação Urbana. Nesta seção, analisa-se a Educação Urbana, dimensionada em três períodos, considerados relevantes para a história do município: Da escola Isolada Lovat (1937) ao Grupo Escolar Mandaguari (1946); A educação urbana: Da criação do Ginásio Estadual de Mandaguari (1949) ao Complexo Escolar professora Hilda de Oliveira (1973 a 1988); A Educação Rural (a partir da década de 1950 a meados de 1980).

Em meados de 1937, ano da fundação povoado Vitória (atual município de Mandaguari), havia uma escola denominada "Escola Isolada de Lovat", mas não foi 
possível comprovar sua existência por meio de documentos, já que, até a presente data, não foram encontradas informações nos arquivos disponibilizados para a pesquisa.

Destarte, a primeira escola oficial foi instituída a partir da década de 1940, revela Silva (1982, p. 179): “A primeira escola sistemática [...], denominada: Grupo Escolar de Lovat, posteriormente Grupo Escolar de Mandaguari”.

Em meados de 1949, foi inaugurado em Mandaguari o novo prédio de alvenaria do Grupo Escolar que comportou as seguintes escolas: Escola de Aplicação de Mandaguari (1958 a 1968); Grupo Escolar Noturno de Mandaguari; Colégio Técnico Comercial Barão do Cerro Azul; Escola Normal Ginasial Manuel Ribas (1949 a 1967); Ginásio Estadual Vera Cruz (1949); Escola Normal Colegial Estadual "Princesa Isabel" (1956 a 1977).

Sobre a escola Normal Regional Manoel Ribas (1949 a 1967), encontram-se, nos arquivos da documentação escolar do município, dados de grande relevância sobre o processo de sua constituição. As atas existentes na secretaria da atual Escola Yolanda Cercal da Silva (1971) - na qual se localizava a $28^{\mathrm{a}}$ inspetoria do município -, registram que eram realizados exames orais e escritos sobre o conteúdo das disciplinas para a aprovação nas séries do curso normal da referida escola. As atas de exames que permaneceram nos arquivos escolares são de 1964, assinadas pela diretora Yolanda Cercal da Silva.

A Lei Orgânica do Ensino Normal de 1946 legisla a respeito da estrutura, organização e das disciplinas desses cursos, que se estenderam pelo solo brasileiro, inclusive o paranaense. Para o ensino normal, de acordo com o disposto em seu artigo $1^{\circ}$, estabelecia os seguintes objetivos: "Prover à formação do pessoal docente necessário às escolas primárias, habilitar administradores escolares destinados às mesmas escolas e desenvolver e propagar os conhecimentos e técnicas relativas à educação da infância." (BRASIL, 1946). O Curso Normal seria ministrado em dois ciclos. Compreendia o curso de regentes de ensino primário (quatro anos) e o curso de formação de professores primários (três anos). Oferecia cursos de especialização para professores primários e cursos de "[...] habilitação para administradores escolares do grau primário", conforme disposto nos artigos $2^{\circ}$ e $3^{\circ}$ da Lei Orgânica $n^{\circ} 8.530$, de 02 de janeiro de 1946. (BRASIL, 1946).

Mediante o arquivo de documentos do município, foram encontradas informações sobre a Escola Normal Ginasial Manuel Ribas datadas de 1964. Constatou-se que a referida Escola não possuía prédio próprio, funcionava no prédio do Grupo Escolar do Município ( $08 \mathrm{~h}$ às $12 \mathrm{~h}$ e $13 \mathrm{~h}$ às $17 \mathrm{~h}$ ). Segundo dados disponíveis nos arquivos de documentação escolar, a quantidade de alunos que frequentavam as séries do Curso Normal era de 162 alunos. Quanto à direção, estava a cargo da professora Yolanda Cercal da Silva (Normalista pelo Instituto de Educação em Curitiba) (ESCOLA MUNICIPAL PROFESSORA YOLANDA CERCAL, 1971).

QUADRO 3- Instituições que funcionaram no prédio do Grupo Escolar de Mandaguari

\begin{tabular}{|l|l|}
\hline Ensino Primário & Horário de funcionamento \\
\hline Escola de Aplicação Gabriela Mistral & $08 \mathrm{~h}$ às $11 \mathrm{~h}, 11 \mathrm{~h}$ às $14 \mathrm{~h}$ e das $14 \mathrm{~h}$ às $17 \mathrm{~h})$ \\
\hline Grupo Escolar Noturno de Mandaguari & $(17 \mathrm{~h}$ às $22 \mathrm{~h})$ \\
\hline $\begin{array}{l}\text { Colégio Técnico Comercial Barão do } \\
\text { Cerro Azul }\end{array}$ & $(17 \mathrm{~h}$ às $22 \mathrm{~h})$ \\
\hline Secundário Ginasial & \\
\hline Escola Normal Ginasial Manuel Ribas & $(08 \mathrm{~h}$ às $12 \mathrm{~h}$ e $13 \mathrm{~h}$ às $17 \mathrm{~h})$ \\
\hline Ginásio Estadual Vera Cruz & $(08 \mathrm{~h}$ às $12 \mathrm{~h}, 13 \mathrm{~h}$ às $17 \mathrm{~h}$ e das $19 \mathrm{~h}$ às $22 \mathrm{~h})$ \\
\hline Secundário Colegial & $(08 \mathrm{~h}$ às $12 \mathrm{~h})$ \\
\hline $\begin{array}{l}\text { Escola Normal Colegial Estadual } \\
\text { "Princesa Isabel" }\end{array}$ & \\
\hline
\end{tabular}


A Escola Normal Ginasial "Manoel Ribas" foi a primeira escola profissionalizante do município de Mandaguari. O ensino Normal Ginasial tinha duração de quatro anos e os alunos que o concluíam estavam aptos a atuar como professores do município.

Dispunha o Art. 4": "Haverá três tipos de estabelecimentos de ensino normal: o curso normal regional, a escola normal e o instituto de educação" (BRASIL, 1946), sendo que o curso normal regional referia-se ao primeiro ciclo; a escola normal ao segundo ciclo e ciclo ginasial do ensino secundário. Já os institutos de educação, além de ministrarem cursos próprios da escola normal, poderiam atender ao curso de especialização, voltado para os professores primários e de habilitação para administradores escolares.

Em 1955, era significativo o número de pessoas que concluíam o primeiro ciclo do curso ginasial e, como o município não possuía um curso para dar sequência aos estudos, acabavam buscando centros maiores para cursarem o segundo ciclo ou Normal Colegial. Esta situação levou a diretora da Escola Normal Regional Manoel Ribas, professora Yolanda Cercal da Silva, a se empenhar, juntamente com todos os professores, pela criação da Escola Normal Secundária.

Em meados de 1956, por intermédio do Decreto $n^{\circ} .2 .123$ (SILVA, 1977) criou-se a Escola Normal Secundária de Mandaguari, que iniciou as suas atividades no prédio do Grupo Escolar do Município. Em 1958, a escola recebeu a seguinte denominação: Escola Normal Secundária "Princesa Isabel" por intermédio do "[...] Decreto no. 13.995, de 23 de janeiro de 1958.” (SILVA, 1977, n. p).

O Grupo Escolar de Mandaguari transformou-se em Escola de Aplicação e, em 1968, denominou-se: Escola de Aplicação "Gabriela Mistral". No referido prédio, funcionaram as seguintes escolas: primeiro Grupo Escolar de Mandaguari, primeira Escola Normal Regional, primeiro Ginásio Estadual de Mandaguari, primeira Escola Normal Secundária, primeiro Colégio Técnico em Contabilidade, primeiro Grupo Escolar Noturno, o Núcleo de Artes Industriais, a Faculdade de Filosofia Ciências e Letras de Mandaguari e a $28^{\mathrm{a}}$ Inspetoria Regional de Ensino.

A própria legislação vigente orientava nesse sentido:

Todos os estabelecimentos de ensino normal manterão escolas primárias anexas para demonstração e prática de ensino.

$\S 1^{\circ}$ Cada curso normal regional deverá manter, pelo menos, duas escolas primárias isoladas.

$\S 2^{\circ}$ Cada escola normal manterá um grupo escolar.

$\S 3^{\circ}$ Cada instituto de educação manterá um grupo escolar e um jardim de infância.

Art. 48. Além das escolas primárias referidas no artigo anterior, cada escola normal e cada instituto de educação deverá manter um ginásio, sob o regime de reconhecimento oficial (BRASIL, 1946.).

Assim, em Mandaguari, a Escola Normal "Manoel Ribas" e a Escola Normal Regional "Princesa Isabel" foram responsáveis pelos cursos de magistério voltados à formação de professores primários. Elas atendiam ao artigo 47 que reza "Todos os estabelecimentos de ensino normal manterão escolas primárias anexas para demonstração e prática de ensino" (BRASIL, 1946) já que ambas eram mantidas nas dependências do Grupo Escolar.

O Município de Mandaguari, ao se emancipar politicamente, teve como prefeito o Sr. Décio Medeiros Pulin, que esteve à frente no processo de criação do primeiro Ginásio para o município. A luta em prol da criação do Ginásio, segundo Silva (1982), “[...] partiu 
dos moradores da região, liderados pelo prefeito municipal que enviou à Secretaria do Estado de Educação e Cultura um documento que solicitava a criação do Ginásio Estadual de Mandaguari, todavia o mesmo foi instituído em 21 de novembro de 1949, por intermédio do Decreto $\mathrm{n}^{\circ}$. 9.137, iniciando as suas atividades em 1950". (COLÉGIO ESTADUAL VERA CRUZ, 1959a).

Segundo os dados obtidos nos arquivos da instituição (COLÉGIO ESTADUAL VERA CRUZ, 1949), o Ginásio Estadual de Mandaguari teve como primeiro diretor o Dr. João Paulino Vieira Filho, que contava, em 1950, com 113 alunos matriculados nas várias séries ginasiais. O Ginásio formou, em 1952, a sua primeira turma composta de nove alunos. Inicialmente, o Ginásio Estadual de Mandaguari funcionava nas dependências do Grupo Escolar de Mandaguari (atual prédio da Escola Professora Yolanda Cercal da Silva).

O Decreto $\mathrm{n}^{\circ}$. 19.628, de 21 de novembro de 1959, alterou a denominação do Ginásio Estadual de Mandaguari para Ginásio Estadual Vera Cruz, em homenagem a um dos nomes que o território brasileiro recebeu quando era colônia de Portugal (COLÉGIO ESTADUAL VERA CRUZ, 1959b).

É necessário reconhecer que a aprovação da Lei de Diretrizes e Bases da Educação Nacional, a Lei $n^{\circ}$. 4.024, promulgada em 20 de dezembro de 1961, representou um crescente avanço para o processo educacional no país, em especial para as instituições que estavam sendo fundadas em Mandaguari.

Em meados de 1962, a incumbência pela educação mandaguariense ficou a cargo da $28^{\text {a }}$ Inspetoria de Ensino, que foi instalada na administração do prefeito Manuel Donha Sanches. Tinha como finalidades: supervisionar as instituições municipais e particulares, manter e aprimorar o desenvolvimento e funcionamento "[...] da rede escolar de ensino: Jardim de Infância, Pré- Escolar, $1^{\circ}$ grau Regular e Supletivo, Educação Especial e $2^{\circ}$ grau, mantido pelo Estado do Paraná", conforme explicita Silva (1982, p. 158).

Silva (1982) informa que a $28^{\text {a }}$ Inspetoria Regional de Ensino funcionava em uma das salas da Escola Paroquial São Vicente Pallotti, contando, inicialmente, com poucos recursos para o seu funcionamento. Entretanto ela obteve apoio da comunidade mandaguariense, que não só respondia pelas instituições já existentes como aquelas fundadas a partir da década de 1960: Ginásio de Mandaguari (Colégio Estadual Vera Cruz); Grupo Escolar "Unidade Nova"; Escola "Bom Pastor" - Ensino Regular e Supletivo; Unidade Pólo - Escola "Luiz Gori" - Ensino de $1^{\circ}$ Grau; Escola "Princesa Isabel" - Ensino de $1^{\circ} \mathrm{Grau}$; Escola "Marechal Costa e Silva" - Ensino de $1^{\circ} \mathrm{Grau}$; Escola "São Vicente Pallotti"; Escola "Sagrada Família".

Em relação a Educação rural o cenário educacional mandaguariense foi marcado por aproximadamente 35 escolas isoladas, possuindo características semelhantes. Eram, normalmente, construídas em madeira, com estruturas precárias, contando com poucos recursos e apenas um professor responsável pela escola, que, além de ensinar, realizava outras funções, tais como: abertura e fechamento da escola; preparação da merenda; realização da faxina e exercia o cargo do diretor, por ser o único responsável pela escola. Para tanto, pode-se considerar que, nas escolas isoladas mandaguarienses, ao se atribuir vários cargos a um único professor, os custos estavam sendo reduzidos e tal ação demonstrava desvalorização desse profissional.

O depoimento da professora Elizabeth Navegante Pereira comprova o desempenho polivalente do professor na escola isolada, que, além de ministrar aulas em salas multisseriadas, a professora exercia a função de merendeira e faxineira, tarefas comuns para o professor primário das escolas isoladas. As instalações da escola eram precárias, carteiras duplas, entre outros aspectos. 
Pelos arquivos disponibilizados para a pesquisa, pode-se afirmar que as mesmas foram instituídas na década de 1950 e extintas a partir da década de 1980, entretanto os originais das referidas legislações não foram encontrados. Ao consultar sobre a sua disponibilidade nos arquivos da prefeitura municipal, foi dada a informação de que as leis não permaneceram nos arquivos, visto que muitas das escolas não pertencem mais ao município em decorrência do desmembramento dos distritos que, até então, faziam parte do território mandaguariense.

É fundamental considerar que as escolas citadas se localizavam na zona rural do município e foram criadas para atender à grande demanda de alunos que viviam fora das cidades. Acrescenta-se que as escolas rurais possuíam características semelhantes às antigas escolas isoladas (que tiveram início no período imperial): o ensino não seriado, apenas um professor responsável por todos os anos, a professora, além de ministrar aulas, cuidava da limpeza e do preparo da merenda para os alunos.

\section{CONSIDERAÇÕES FINAIS}

A experiência de ir ao encontro de fontes instigou o desejo de aliar ao trabalho dissertativo a pesquisa qualitativa, que se obteve por intermédio da história oral. As lacunas não preenchidas pelas fontes pesquisadas, foram supridas por intermédio dos depoimentos, possibilitando conhecer um pouco mais da história do município, das práticas escolares, da organização do trabalho pedagógico nas escolas urbanas e nas escolas isoladas e da formação dos professores. O estudo trouxe à tona memórias individuais que se tornaram, ao longo da pesquisa, memórias coletivas.

As informações proporcionadas pelas fontes revelaram as lacunas de um passado que pôde ser investigado por intermédio do olhar do pesquisador a partir do presente. Desse modo, sem o conjunto de fontes pode-se dizer que não há pesquisa. Netto (2006, p. 52) afirma que "[...] o que garante o êxito da pesquisa, da investigação, é a riqueza cultural do sujeito que pesquisa. Investigador ignorante, pesquisa estreita. Investigador rico, resultados fecundos e instigantes".

Ao entrevistar os sujeitos que participaram e/ ou participam desse processo, foi possível perceber que a instituições escolares acompanharam os movimentos contraditórios da sociedade. Os depoimentos orais foram os mediadores para a investigação do passado. Um passado que, apesar de não ter sido reconstituído em sua totalidade, permitiu novos olhares, críticas e questionamentos a favor das instituições escolares mandaguariense.

Destacar que não temos a história das instituições escolares, mas que são muitas as histórias, indica também que não se pretende compor uma visão única, fixista, verdadeira. Esta pluralidade de histórias e a multiplicidade de fontes indicam a multidimensionalidade daquilo que é chamado de história das instituições escolares. (WERLE, 2004, p. 29).

A investigação sobre a história do Paraná permitiu avançar sobre o território, compreender seus avanços no cenário educacional, econômico e social, possibilitando chegar à história do recorte espacial que teve como palco: o Município de Mandaguari, sendo possível descrever e analisar os seus aspectos políticos, econômicos e, especialmente, educacionais. Contribuiu para o reconhecimento do município no cenário brasileiro e paranaense por intermédio de sua história, do conjunto de fontes e, especialmente, por investigar a memória oral de ex- professores e ex-alunos que participaram/participam da educação no referido município. 


\section{REFERÊNCIAS}

BRASIL. Lei Orgânica do Ensino Normal. Decreto-lei no 8.530, de 02 de janeiro de 1946. Disponível em: <http://www.soleis.adv.br/leiorganicaensinonormal.htm>. Acesso em: 25 jul. 2009.

CAMARGO, João Borba de. História do Paraná (1889-2003). Maringá, PR: Gráfica Maranata, 2006.

COMPANHIA MELHORAMENTOS NORTE DO PARANÁ. Colonização e desenvolvimento do norte do Paraná. São Paulo: Cia Melhoramentos Norte do Paraná, 1975.

LAZIER, Hermógenes. Paraná: Terra de todas as gentes e de muita história. Francisco Beltrão: Grafit-gráfica e Editora Ltda, 2003.

LUZ, France. O fenômeno urbano numa zona pioneira: Maringá. Maringá: A Prefeitura, 1997.

FONTES. Elizabeth Ana; BIANCHINI. Nair de Matos. Mandaguari e sua história. Maringa, PR: Gráfica Clichetec. 1987.

MIGUEL, Maria Elisabeth Blanc. A escola normal no Paraná: instituição formadora de professores e educadora do povo. In: ARAUJO, Jose Carlos Souza; FREITAS, Anamaria Gonçalves Bueno de; LOPES, Antonio de Pádua Carvalho. As escolas normais no Brasil: Do Império à República. Campinas, SP: Alínea, 2008. p. 145-161.

NOELLI, Francisco Silva; MOTA, Lúcio Tadeu. A pré- história da região onde se encontra Maringá, Paraná. In: DIAS, Reginaldo Benedito; GONÇALVES, José Henrique Rollo (Orgs.). Maringá e o norte do Paraná: estudos de história regional. Maringá, PR: EDUEM,1999. Cap.1, p.5-20.

PROSSER, Elizabeth Seraphim. Cem anos de sociedade, arte e educação em Curitiba: 1853 - 1953: De Escola de Belas Artes e Indústrias de Mariano de Lima, à Universidade do Paraná e à Escola de Música e Belas Artes do Paraná. Curitiba: Imprensa Oficial, 2004.

SAVIANI, Dermeval. Breves considerações sobre fontes para a história da educação. In: LOMBARDI, José Claudinei; NASCIMENTO, Maria Isabel Moura (Orgs.). Fontes, história e historiografia da educação. Campinas, SP: Autores Associados, 2004. cap. 1, p. 3-12.

SILVA, José Adalberto Firmino. Mandaguari e sua história. Maringá, PR, 1982.

TRINDADE, Etelvina Maria de Castro; ANDREAZZA,Maria Luiza. Cultura e educação no Paraná. Curitiba: SEED, 2001.

WACHOWICZ, Ruy Christowam. História do Paraná. 6. ed. ampliada. Curitiba: Editora Gráfica Vicentina Ltda, 1988. 
História do Paraná. 9. ed. Curitiba: Imprenssa Oficial do Paraná, 2001. 360 p.

\section{FONTES CONSULTADAS}

COLÉGIO ESTADUAL VERA CRUZ. Dados referentes à atual escola. In: Pasta geral da escola. Mandaguari: Secretaria, 1949. Não paginado.

Pasta de fotos. Mandaguari: Secretaria, 1950. Não paginado.

Decreto $n^{\circ}$. 9.137. In:

Pasta de documentos oficiais. Mandaguari:

Secretaria, 1959a. Não paginado.

Decreto $n^{\circ}$. 19.628. In: . Pasta de documentos oficiais. Mandaguari:

Secretaria, 1959b. Não paginado.

Decreto $n^{\circ}$. 4.019. In:

Pasta de documentos oficiais. Mandaguari: Secretaria, 1977. Não paginado.

. Matrículas de alunos do $1^{\mathrm{a}} \operatorname{Grau}\left(1950\right.$ a 1959) e matrículas dos alunos do $2^{\mathrm{a}}$ Grau(1967 a 1977) . In: . Pasta geral da escola. Mandaguari: Secretaria, 1977. Não paginado.

. Preâmbulo (informações sobre as escolas que foram organizadas pelo Complexo Escolar Professora Hilda de Oliveira). In: . Pasta geral da escola. Mandaguari: Secretaria, 1977. Não paginado.

Decreto $n^{\circ}$. 2.057. In: Pasta de documentos oficiais. Mandaguari: Secretaria, 1980. Não paginado.

Resolução no . 253/82. In: Pasta de documentos oficiais. Mandaguari:

Secretaria, 1982. Não paginado.

Resolução $n^{\circ}$. 4.094. In: Pasta de documentos oficiais. Mandaguari: Secretaria, 1985a. Não paginado.

Resolução no. 2.607. In: Pasta de documentos oficiais. Mandaguari: Secretaria, 1987. Não paginado.

COLÉGIO ESTADUAL DE MANDAGUARI. Livro de médias. Mandaguari: Secretaria, referente aos anos 1950,1951, 1952.

ESCOLA MUNICIPAL PROFESSORA YOLANDA CERCAL. Primeiros dias da Vila. In: . Pasta de documentos sobre a escola e a história do município. Mandaguari: Secretária, 1971. Manuscrito. Não paginado.

MIOTO, Pedro. Trabalho mimeografado sobre Mandaguari (Encontrado nos arquivos da documentação escolar do município). 1977. Não paginado. 
SILVA, Ana Rosa Garcia da et al. Projeto de Cooperação e Assistência Técnica ao Ensino Municipal (Promunícipio). In: Biblioteca Municipal Dr. Alcir Castelo Branco. mimiografado.1977. $337 \mathrm{p}$.

Notas

${ }^{1}$ Mestre em Educação (2012). Atua como professora do ensino fundamental no município de Mandaguari e tutora a distância do curso de pedagogia da Universidade Estadual de Maringá.

${ }^{2}$ Doutora em Educação. Professora da Universidade Estadual de Maringá. E-mail mcgmachado@uem.br.

Recebido em: $\quad 08.05 .12$

Aprovado em: $\quad 30.05 .12$ 